\title{
Compact ultrabroadband light-emitting diodes based on lanthanide-doped lead-free double perovskites
}

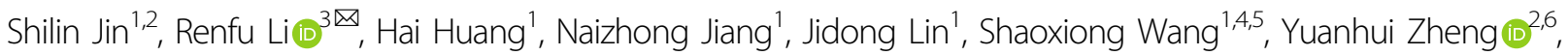 \\ Xueyuan Chen $\mathbb{1}^{3 \times}$ and Daqin Chen (10) ${ }^{1,2 \times}$
}

\begin{abstract}
Impurity doping is an effective approach to tuning the optoelectronic performance of host materials by imparting extrinsic electronic channels. Herein, a family of lanthanide $\left(\mathrm{Ln}^{3+}\right)$ ions was successfully incorporated into a Bi:Cs $2 \mathrm{AgInCl}_{6}$ lead-free double-perovskite (DP) semiconductor, expanding the spectral range from visible (Vis) to near-infrared (NIR) and improving the photoluminescence quantum yield (PLQY). After multidoping with $\mathrm{Nd}, \mathrm{Yb}, \mathrm{Er}$ and Tm, Bi/Ln: $\mathrm{CS}_{2} \mathrm{AgInCl}_{6}$ yielded an ultrabroadband continuous emission spectrum with a full width at half-maximum of $\sim 365 \mathrm{~nm}$ originating from intrinsic self-trapped exciton recombination and abundant $4 \mathrm{f}-4 \mathrm{f}$ transitions of the $\mathrm{Ln}^{3+}$ dopants. Steady-state and transient-state spectra were used to ascertain the energy transfer and emissive processes. To avoid adverse energy interactions between the various $\mathrm{Ln}^{3+}$ ions in a single DP host, a heterogeneous architecture was designed to spatially confine different $\mathrm{Ln}^{3+}$ dopants via a "DP-in-glass composite" (DiG) structure. This bottom-up strategy endowed the prepared $\mathrm{Ln}^{3+}$-doped DIG with a high PLQY of 40\% (nearly three times as high as that of the multidoped DP) and superior long-term stability. Finally, a compact Vis-NIR ultrabroadband (400 2000 nm) light source was easily fabricated by coupling the DiG with a commercial UV LED chip, and this light source has promising applications in nondestructive spectroscopic analyses and multifunctional lighting.
\end{abstract}

\section{Introduction}

Ultrabroadband light sources that emit over an extremely wide spectral range are of great interest in many fields, such as photonics, medical treatment, high-capacity optical data communications, ultraprecision metrology, and spectroscopy ${ }^{1-7}$. Conventionally, halogen tungsten lamps (HTLs) are used in most studies and applications, but they generate large amounts of heat and have limited operational lifetimes ${ }^{8}$. Recently, superluminescent diodes $(\mathrm{SLDs})^{9}$, ultrabroadband semiconductor lasers $(\mathrm{UBSLs})^{10}$,

Correspondence: Renfu Li (lirenfu@fjirsm.ac.cn) or

Xueyuan Chen (xchen@fjirsm.ac.cn) or Daqin Chen (dqchen@fjnu.edu.cn)

${ }^{1}$ College of Physics and Energy, Fujian Normal University, Fujian Provincial Key

Laboratory of Quantum Manipulation and New Energy Materials, Fuzhou

350117, China

${ }^{2}$ Fujian Science \& Technology Innovation Laboratory for Optoelectronic Information, Fuzhou 350116, China

Full list of author information is available at the end of the article laser-driven light sources $(\mathrm{LDLSs})^{11}$, supercontinuum light sources $(\mathrm{SCLSs})^{12}$, and other sources of light have been developed to satisfy the needs of various applications. SLDs are fabricated by elaborately coupling many light-emitting diodes (LEDs) with different emission wavelengths. UBSLs adopt a quantum cascade configuration, where several dissimilar inter-subband (IS) optical transitions cooperate to provide broadband optical gain. LDLSs use high-power lasers to energize highintensity xenon $(\mathrm{Xe})$ plasma, which produces broadband radiation. SCLSs are generated in a photonic crystal fiber pumped by a femtosecond laser. Notably, each of these approaches has intrinsic drawbacks, such as complex structure design for coupling multiple LEDs, difficulty in tailoring IS transitions, low efficiency, and expensive laser triggers.

\section{(c) The Author(s) 2022}

(c) (i) Open Access This article is licensed under a Creative Commons Attribution 4.0 International License, which permits use, sharing, adaptation, distribution and reproduction cc) in any medium or format, as long as you give appropriate credit to the original author(s) and the source, provide a link to the Creative Commons license, and indicate if changes were made. The images or other third party material in this article are included in the article's Creative Commons license, unless indicated otherwise in a credit line to the material. If material is not included in the article's Creative Commons license and your intended use is not permitted by statutory regulation or exceeds the permitted use, you will need to obtain permission directly from the copyright holder. To view a copy of this license, visit http://creativecommons.org/licenses/by/4.0/. 
Lanthanide $\left(\mathrm{Ln}^{3+}\right)$ or rare-earth ion incorporation or doping is considered a promising approach to imparting and tailoring the optical and optoelectronic performances of inorganic materials spanning the ultraviolet (UV), visible (Vis), near-infrared (NIR), and middle-infrared (MIR) regions, improving their abundant intermediate excited states $^{13}$. For example, Er-doped fiber amplification (EDFA), praseodymium-doped fiber amplifier (PDFA), and thuliumdoped fiber amplifier (TDFA) with broadband NIR emissions have been successfully applied in optical telecommunication $^{14-16}$. However, the parity-forbidden $4 \mathrm{f}-4 \mathrm{f}$ transition of $\mathrm{Ln}^{3+}$ leads to weak light absorption, which limits the practical application of these materials. Sensitizing $\mathrm{Ln}^{3+}$ emission via semiconductor quantum dots (QDs) can effectively address this difficult challenge because QDs undergo efficient allowed band-to-band absorption and have tuneable bandgaps ${ }^{17}$. Recently, various lanthanide ions have been successfully doped into the hottest lead-halide perovskite QD (PeQD) lattices to endow them with optical functionality ${ }^{18-21}$. Unfortunately, their use of toxic lead and their poor stability to heat, water, electric fields, and light hamper their commercialization and industrialization on a large scale ${ }^{22,23}$. As an alternative, lead-free halide double perovskites $\left(\mathrm{DP}_{\mathrm{S}}\right)$ have drawn extensive attention for their fascinating optical performance and excellent stability ${ }^{24-26}$. Among the DP family, $\mathrm{Cs}_{2} \mathrm{AgInCl}_{6}$ has been in the spotlight for its direct bandgap characteristics and various alloy compositions with monoand trivalent cations other than $\mathrm{Ag}^{+}$and $\mathrm{In}^{3+27-29}$. For example, $\mathrm{Cs}_{2} \mathrm{AgInCl}_{6}$ alloyed with $40 \% \mathrm{Na}^{+}$and $0.04 \% \mathrm{Bi}^{3+}$ doping emits warm white light with $\sim 86 \%$ photoluminescence quantum yield (PLQY) and works beyond $1000 \mathrm{~h}$ without obvious PL $\operatorname{loss}^{30}$. The underlying mechanism of the broadband luminescence in the visible $(400 \sim 800 \mathrm{~nm})$ spectral range proceeded via the recombination of self-trapped excitons (STEs), which mainly arose from the strong Jahn-Teller distortion of the $\mathrm{AgCl}_{6}$ octahedron triggered by $\mathrm{Na}^{+}$dopants ${ }^{30}$. Since then, several successful examples of DPs doped with $\mathrm{Ln}^{3+}$ ions (Table $\mathrm{S} 1$ ), including La-, Tb-, Er-, and $\mathrm{Yb}$-doped $\mathrm{Cs}_{2} \mathrm{AgInCl}_{6}$, have been reported, primarily for their potential applications in white-light-emitting diodes (wLEDs), NIR-LEDs with specific wavelengths, scintillators, anticounterfeiting techniques, and X-ray detection and imaging ${ }^{31-45}$.

Inspired by the studies described above, we intend to explore the possibility of combining the STE recombination of $\mathrm{Cs}_{2} \mathrm{AgInCl}_{6}$ with $\mathrm{Ln}^{3+}$ dopant-induced extra lightemitting channels to produce lead-free Vis-NIR (400 2000 nm) ultrabroadband emissive DPs for the first time. To our knowledge, there has been no report on $\mathrm{Ln}^{3+}$-doped DPs aimed at the application of ultrabroadband light sources. Herein, a family of $\mathrm{Ln}^{3+}$ dopants $(\mathrm{Ln}=\mathrm{La}-\mathrm{Lu})$ with $\mathrm{Bi}^{3+}$ ions is successfully incorporated into $\mathrm{Cs}_{2} \mathrm{AgInCl}_{6}$ DPs. The $\mathrm{Bi} / \mathrm{Ln}(\mathrm{Ln}=\mathrm{Nd}, \mathrm{Yb}, \mathrm{Er}$, and
$\mathrm{Tm}): \mathrm{Cs}_{2} \mathrm{AgInCl}_{6}$ samples can yield both visible STE radiation and multiple NIR $\mathrm{Ln}^{3+} 4 \mathrm{f}-4 \mathrm{f}$ emissions under UV light excitation, and the related energy transfer mechanisms are systematically discussed. We further provide a strategy of dispersing $\mathrm{Nd}: \mathrm{Cs}_{2} \mathrm{AgInCl}_{6}, \mathrm{Yb} / \mathrm{Er}$ : $\mathrm{Cs}_{2} \mathrm{AgInCl}_{6}$, and $\mathrm{Yb} / \mathrm{Tm}: \mathrm{Cs}_{2} \mathrm{AgInCl}_{6}$ DPs into an inorganic glass matrix to prevent the depletion of nonradiative migration from the co-doping of multiple $\mathrm{Ln}^{3+}$ ions in a sole DP host, leading to detrimental luminescent quenching. To the best of our knowledge, this is the first report on a DP-in-glass (DiP) composite. The DiP composite with superior stability and a high PLQY of $\sim 40 \%$ can be coupled with a commercial UV LED chip to construct an ultrabroadband LED (u-LED) device. Finally, we demonstrate its promising applications in spectroscopic analysis and multifunctional lighting. Notably, compared with previously reported ultrabroadband light sources, this u-LED device shows the advantages of costeffective fabrication, compactness, excellent optical performance and extremely long-term stability.

\section{Results and discussion}

$\mathrm{Bi} / \mathrm{Ln}$-doped $\mathrm{Cs}_{2} \mathrm{AgInCl}_{6}$ DPs were synthesized via a modified coprecipitation method (Fig. S1, Experimental Section) previously reported by Volonakis et $\mathrm{al}^{27}$. In a typical synthesis, stoichiometric amounts of $\mathrm{InCl}_{3}, \mathrm{AgCl}$, $\mathrm{BiCl}_{3}$, and $\mathrm{LnCl}_{3}$ are dissolved in hydrochloric acid at $100{ }^{\circ} \mathrm{C}$. Upon the addition of $\mathrm{CsCl}$ solution, a precipitate forms after 20 min of reaction. Notably, a shaded glass bottle is needed in the synthesis of DPs to prevent the silver chloride from being oxidized (Supporting Information, Movie 1). We first prepared $\mathrm{Cs}_{2} \mathrm{AgInCl}_{6} \mathrm{DPs}$ doped with only $\mathrm{Bi}^{3+}$ and investigated the influence of $\mathrm{Bi}^{3+}$ doping content on the structure and optical properties. The X-ray diffraction (XRD) patterns showed that the pure cubic phase was retained after $\mathrm{Bi}^{3+}$ doping (Fig. S2a). With increasing $\mathrm{Bi}^{3+}$ content, the diffraction peaks shifted slightly to a lower angle (Fig. $\mathrm{S} 2 \mathrm{~b})$, indicating the substitution of $\mathrm{In}^{3+}$, which has a small ionic radius $(r=0.80 \AA, \mathrm{CN}=6)$, with $\mathrm{Bi}^{3+}$, which has a large ionic radius $(r=1.02 \AA, \mathrm{CN}=6)$. PL originating from STE recombination for the $\mathrm{Cs}_{2} \mathrm{AgInCl}_{6} \mathrm{DPs}$ is quite weak, and the corresponding PLQY is lower than $1 \%$; $\mathrm{Bi}^{3+}$ doping will significantly improve the PL intensity, decay lifetime, and PLQY up to $\sim 25 \%$ for STE emission (Fig. S2c, Fig. S2d, Fig. S3). The optimal $\mathrm{Bi}^{3+}$ nominal doping content is $0.048 \mathrm{mmol}$ (Fig. S3), which corresponds to the actual content of $\sim 15 \mathrm{~mol} \%$ determined by inductively coupled plasma-mass spectrometry (ICP-MS) (Table S2). The excitation power (intensity)- and temperature-dependent PLQYs of $\mathrm{Bi}$ : $\mathrm{Cs}_{2} \mathrm{AgInCl}_{6}$ were determined. The PLQY remained unchanged with increasing excitation power and was insensitive to excitation intensity (Fig. S3d). However, 
with increasing temperature, the PLQY showed a tendency to decrease owing to thermal quenching of STE recombination (Fig. S3e). The normalized PL/PLE spectra show redshifting of both the emission and excitation bands with increasing $\mathrm{Bi}^{3+}$ content (Fig. S2e, $\mathrm{S} 2 \mathrm{f}$ ), indicating the $\mathrm{Bi}^{3+}$-doping-induced modification of the band-edge structure of $\mathrm{Cs}_{2} \mathrm{AgInCl}_{6} \mathrm{DPs}^{46-49}$. We prepared additional $\mathrm{Bi}^{3+} / \mathrm{Er}^{3+}$ codoped samples with various $\mathrm{Bi}^{3+}$ contents and fixed $\mathrm{Er}^{3+}$ contents. All the samples were assigned to the cubic $\mathrm{Cs}_{2} \mathrm{AgInCl}_{6}$ phase and exhibited sharp emission peaks corresponding to the $\operatorname{Er}^{3+}:{ }^{2} \mathrm{H}_{11 / 2} \rightarrow{ }^{4} \mathrm{I}_{15 / 2},{ }^{4} \mathrm{~S}_{3 / 2} \rightarrow{ }^{4} \mathrm{I}_{15 / 2},{ }^{4} \mathrm{~F}_{9 / 2} \rightarrow{ }^{4} \mathrm{I}_{15 / 2}$, and ${ }^{4} \mathrm{I}_{9 / 2} \rightarrow{ }^{4} \mathrm{I}_{15 / 2}$ transitions in the visible spectral region upon excitation with 250 450 nm light (Fig. S4), confirming the incorporation of the $\mathrm{Er}^{3+}$ dopants into the DP host. With the addition of $\mathrm{Er}^{3+}$ ions, the total emitting intensity was greater than that of the sample doped with only $\mathrm{Bi}^{3+}$ owing to the superposition of the additional $\mathrm{Er}^{3+}$ emissions, and the optimal $\mathrm{Bi}^{3+}$ content remained at $0.048 \mathrm{mmol}$ (Fig. S5). As evidenced in Fig. S6, changing the $\mathrm{Er}^{3+}$ content does not greatly enhance the $\mathrm{Er}^{3+}$ emission intensity. Compared to that of the sample doped with only $\mathrm{Bi}$, the PLQY for the $\mathrm{Er} / \mathrm{Bi}$ codoped sample is greater; however, the PLQY does not noticeably differ for different $\mathrm{Er}^{3+}$-doped samples (Fig. S6). These results indicate the doping saturation of $\mathrm{Er}^{3+}$ ions, which makes high-content $\mathrm{Er}^{3+}$ doping difficult. Indeed, the ICP-MS (Table S2) data verify the saturated doping of $\mathrm{Er}^{3+}$ in DPs with the highest content of $\sim 2.5 \mathrm{~mol} \%$, even when the nominal Er/In doping ratio reaches as high as 3. Similarly, for the $\mathrm{Yb} / \mathrm{Er}$ co-doped sample, the total doping content of both $\mathrm{Yb}$ and $\mathrm{Er}$ is also close to $2.5 \mathrm{~mol} \%$ (Table S2). Indeed, intense upconversion luminescence can be detected from the $\mathrm{Bi} / \mathrm{Yb} / \mathrm{Ln} \quad(\mathrm{Ln}=\mathrm{Er}$, Ho, or $\mathrm{Tm}): \mathrm{Cs}_{2} \mathrm{AgInCl}_{6}$ samples under $980 \mathrm{~nm}$ laser excitation (Fig. S7), further confirming the incorporation of $\mathrm{Ln}^{3+}$ ions in the DP host. Notably, it is easy to incorporate many $\mathrm{Bi}^{3+}$ ions into $\mathrm{Cs}_{2} \mathrm{AgInCl}_{6}$ because the structure of $\mathrm{Cs}_{2} \mathrm{Ag}(\mathrm{In} / \mathrm{Bi}) \mathrm{Cl}_{6}$ is a stable solid solution ${ }^{50}$, while doping $\mathrm{Ln}^{3+}$ ions into $\mathrm{Cs}_{2} \mathrm{AgInCl}_{6}$ is difficult because the electronic configurations of the $\mathrm{Ln}^{3+}$ ions and $\mathrm{In}^{3+}$ ions are quite different.

The XRD patterns for the whole family of Bi-Ln $(\mathrm{Ln}=\mathrm{La}-\mathrm{Lu})$-doped DP samples are provided in Fig. 1a. Introducing $\mathrm{Ln}^{3+}$ dopants does not induce the formation of impurity phases for all the products, and the diffraction peaks were assigned to the cubic $\mathrm{Cs}_{2} \mathrm{AgInCl}_{6}$ phase. The diffraction peak slightly shifted to a smaller angle after the substitution of $\mathrm{In}^{3+}$ by $\mathrm{Ln}^{3}$; this shift was due to the gradual increase in ionic radius from $\mathrm{Lu}^{3+}$ to $\mathrm{La}^{3+}$ (Fig. S8), suggesting successful incorporation of $\mathrm{Ln}^{3+}$ dopants into the $\mathrm{Cs}_{2} \mathrm{AgInCl}_{6}$ crystalline lattice. Taking $\mathrm{Yb} / \mathrm{Er}$ : $\mathrm{Cs}_{2} \mathrm{AgInCl}_{6}$ as a typical example, the scanning electron microscopy (SEM) images show that the products are micron-sized crystals with polygonal shapes (Fig. 1b). Energy-dispersive $\mathrm{X}$-ray (EDX) mappings confirm the uniform distribution of all the elements of $\mathrm{Cs}, \mathrm{Ag}, \mathrm{In}, \mathrm{Cl}$, $\mathrm{Bi}, \mathrm{Yb}$, and $\mathrm{Er}$ (Fig. 1c). The actual elemental content was consistent with the experimental scheme (Fig. S6d, Table S3). X-ray photoelectron spectroscopy (XPS) measurements on the M-1(Bi:Cs $\left.\mathrm{AgInCl}_{6}\right), \mathrm{M}-2$ ( $\mathrm{Bi} / \mathrm{Yb}: \mathrm{Cs}_{2} \mathrm{~A}-$ $\left.\mathrm{gInCl}_{6}\right)$, and $\mathrm{M}-3\left(\mathrm{Bi} / \mathrm{Yb} / \mathrm{Er} \mathrm{Cs}_{2} \mathrm{AgInCl}_{6}\right)$ samples were performed (Fig. S9). Typical Cs 3d, Ag 3d, In 3d, and Cl 2p signal peaks (Fig. S9, Fig. 1d) were detected in the highresolution XPS spectra, and extra Bi $4 \mathrm{f}$ (Fig. 1e), Yb $4 \mathrm{~d}$ (Fig. 1f), and Er 4d (Fig. 1g) peaks were observed for the $\mathrm{Bi} / \mathrm{Yb} / \mathrm{Er} \mathrm{Cs}_{2} \mathrm{AgInCl}_{6}$ sample. Additionally, as shown in Fig. 1d, the shifting of the In $3 \mathrm{~d}$ peak toward higher energy is observed after $\mathrm{Bi} / \mathrm{Yb} / \mathrm{Er}$ doping. Generally, the substitution of $\mathrm{In}^{3+}$ ions by $\mathrm{Bi}^{3+}$ and $\mathrm{Ln}^{3+}$ dopants in $\mathrm{Cs}_{2} \mathrm{AgInCl}_{6}$ leads to lattice expansion and thus a slight shift to a higher binding energy of the $\operatorname{~In~}^{3+} 3 \mathrm{~d}$ XPS peak. Similar results have been observed in $\mathrm{Bi} / \mathrm{Tb}$-doped $\mathrm{Cs}_{2} \mathrm{AgInCl}_{6}$ samples and have been previously reported. ${ }^{38}$ Furthermore, magic-angle-spinning (MAS) solid-state nuclear magnetic resonance (NMR) measurements for ${ }^{133} \mathrm{Cs}$ and ${ }^{115} \mathrm{In}$ were performed on the $\mathrm{Bi}^{1} \mathrm{Cs}_{2} \mathrm{AgInCl}_{6}$ and $\mathrm{Bi} / \mathrm{Yb} / \mathrm{Er} \mathrm{Cs}_{2} \mathrm{AgInCl}_{6}$ samples. The doping of paramagnetic $\mathrm{Yb}^{3+}$ and $\mathrm{Er}^{3+}$ induced a shift of the ${ }^{133} \mathrm{Cs}$ doublet peaks from 105.9/112.3 ppm to 105.4/111.8 ppm (Fig. 1h). This shift is ascribed to the delocalization of the extra electron density of $\mathrm{Yb}^{3+}$ and $\mathrm{Er}^{3+}$ (spin $\mathrm{I}=1 / 2$ and $3 / 2$ ) on the $\mathrm{Cs}^{+}$ion (i.e., the Fermi-contact interaction $)^{41,51-53}$. The two samples show the peaks of ${ }^{115}$ In at $41.8 \mathrm{ppm}$ and $52.3 \mathrm{ppm}$ (Fig. 1i), and the relative peak intensity decreases at $41.8 \mathrm{ppm}$ after Ln doping ${ }^{53}$. The results of the above two changes further verify the successful incorporation of rare-earth ions into the $\mathrm{Cs}_{2} \mathrm{~A}$ $\mathrm{gInCl}_{6}$ DP lattice.

We recorded the PL spectra of all the $\mathrm{Bi} / \mathrm{Ln}$ codoped $\mathrm{Cs}_{2} \mathrm{AgInCl}_{6}$ samples. Under $350 \mathrm{~nm}$ UV light excitation, typical narrow emission peaks assigned to $\mathrm{Ln}^{3+} 4 \mathrm{f} \rightarrow 4 \mathrm{f}$ transitions appeared in addition to the broadband emission of STE for the $\mathrm{Pr}^{3+}, \mathrm{Nd}^{3+}, \mathrm{Sm}^{3+}, \mathrm{Tb}^{3+}, \mathrm{Dy}^{3+}, \mathrm{Ho}^{3+}$, $\mathrm{Er}^{3+}, \mathrm{Tm}^{3+}$, and $\mathrm{Yb}^{3+}$-doped samples (Fig. S10). All the samples exhibited bright luminescence, and the slight difference in emission color is due to the combination of STE emissive color and $\mathrm{Ln}^{3+}$ color (Fig. S11). The corresponding $\mathrm{Ln}^{3+}$ if $\rightarrow$ ff electronic transitions and emitting wavelengths are tabulated in Table S4. For the other $\mathrm{Ln}^{3+}(\mathrm{Ln}=\mathrm{La}, \mathrm{Ce}, \mathrm{Eu}, \mathrm{Gd}$, and $\mathrm{Lu})$-doped samples, only STE emission was observed. $\mathrm{La}^{3+}, \mathrm{Ce}^{3+}, \mathrm{Gd}^{3+}$, and $\mathrm{Lu}^{3+}$ dopants with outer-shell electronic configurations of $4 \mathrm{f}^{0}$, $4 \mathrm{f}^{1}, 4 \mathrm{f}^{7}$, and $4 \mathrm{f}^{14}$ do not have suitable energy levels falling inside the bandgap of $\mathrm{DP}^{13}$, and no energy transfer from DP to them occurs. $\mathrm{Eu}^{3+}$ dopants easily produce electron trapping states in empty f-orbitals in the bandgap ${ }^{36,39}$, 

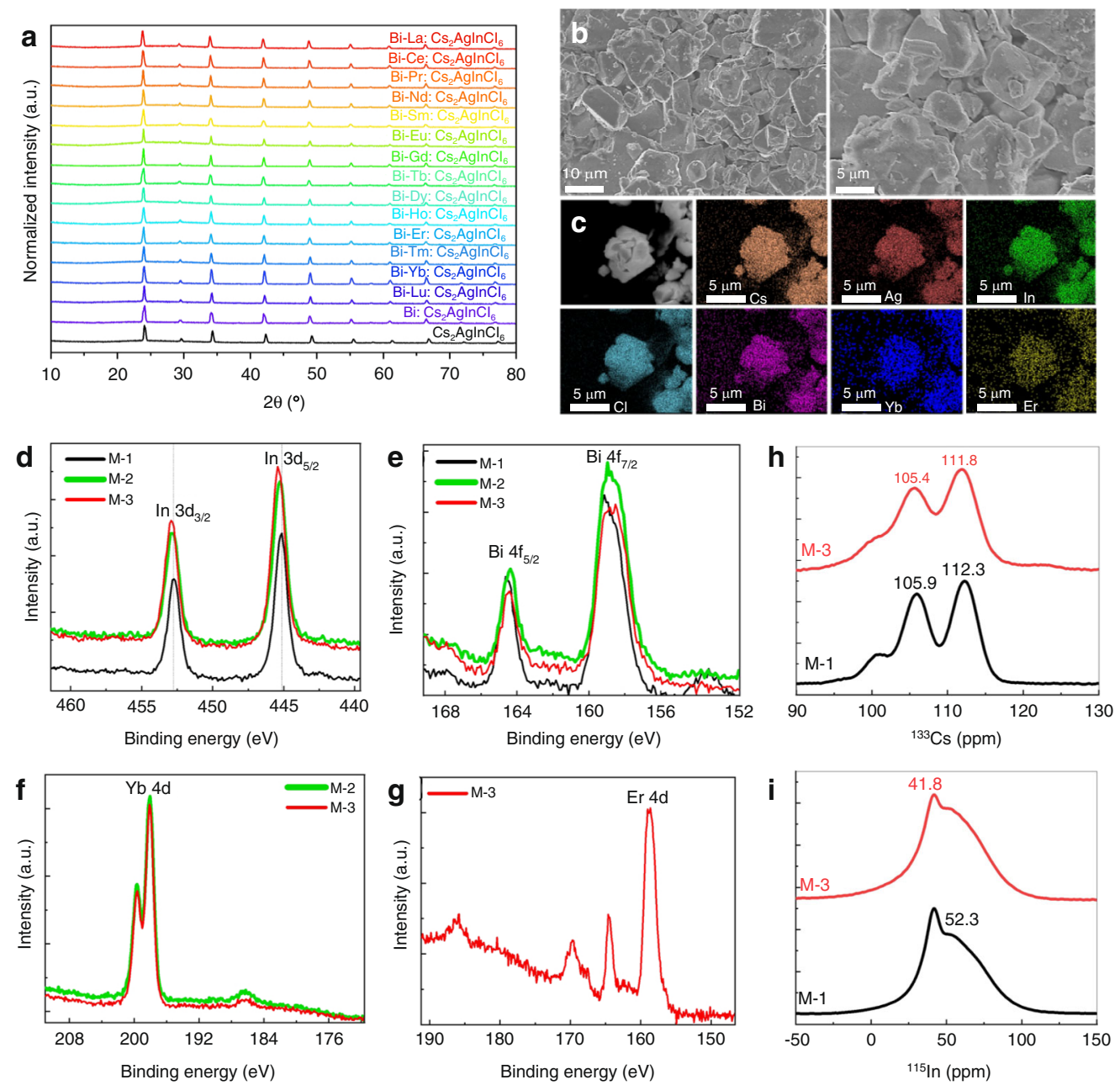

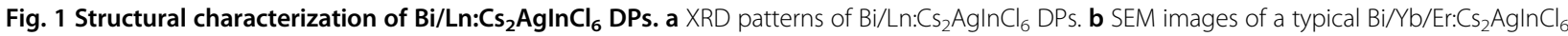
sample and (c) the corresponding EDX mappings. $\mathbf{d}-\mathbf{g}$ XPS spectra of the In 3d, Bi 4f, Yb 4d, and Er 4d orbitals of M-1 (Bi:Cs $\mathrm{Ag} \mathrm{InCl}_{6}$, black line), M-2 (Bi/Yb:Cs ${ }_{2} \mathrm{AgInCl}_{6}$, green line), and $\mathrm{M}-3$ (Bi/Yb/Er:Cs${ }_{2} \mathrm{AgInCl}_{6}$, red line) samples. $\mathbf{h}{ }^{133} \mathrm{Cs}$ and $\mathbf{i}{ }^{115} \mathrm{In} \mathrm{NMR}$ spectra of the $\mathrm{M}-1$ and $\mathrm{M}-3$ samples

which act as quenching centers. Importantly, as demonstrated in Fig. 2a, the combination of STE broadband visible emission $(400-800 \mathrm{~nm})$ with a series of narrowband NIR emissions from $\mathrm{Ln}^{3+}$ ions $\left(\mathrm{Yb}^{3+}:{ }^{2} \mathrm{~F}_{5 / 2} \rightarrow{ }^{2} \mathrm{~F}_{7 / 2}\right.$; $\mathrm{Tm}^{3+}: \quad{ }^{3} \mathrm{H}_{4} \rightarrow{ }^{3} \mathrm{H}_{6}, \quad{ }^{3} \mathrm{H}_{5} \rightarrow{ }^{3} \mathrm{H}_{6}, \quad{ }^{3} \mathrm{H}_{4} \rightarrow{ }^{3} \mathrm{~F}_{4} ; \quad \mathrm{Er}^{3+}$ : ${ }^{4} \mathrm{I}_{11 / 2} \rightarrow{ }^{4} \mathrm{I}_{15 / 2}, \quad{ }^{4} \mathrm{I}_{13 / 2} \rightarrow{ }^{4} \mathrm{I}_{15 / 2} ; \quad \mathrm{Nd}^{3+}: \quad{ }^{4} \mathrm{~F}_{3 / 2} \rightarrow{ }^{4} \mathrm{I}_{9 / 2}$, $\left.{ }^{4} \mathrm{~F}_{3 / 2} \rightarrow{ }^{4} \mathrm{I}_{11 / 2},{ }^{4} \mathrm{~F}_{3 / 2} \rightarrow{ }^{4} \mathrm{I}_{13 / 2}\right)$ is feasible to realize an ultrabroadband continuous emission spectrum. Taking $\mathrm{Bi} / \mathrm{Er}: \mathrm{Cs}_{2} \mathrm{AgInCl}_{6}$ DP as a typical example, the PL excitation (PLE) spectra were recorded by monitoring the various emissions of $\mathrm{Er}^{3+}$ (Fig. 2b). The PLE spectra corresponding to the broad visible-light emission of STE at $610 \mathrm{~nm}$ are similar for both the $\mathrm{Bi}: \mathrm{Cs}_{2} \mathrm{AgInCl}_{6}$ and $\mathrm{Bi}$ / $\mathrm{Er}: \mathrm{Cs}_{2} \mathrm{AgInCl}_{6}$ samples, but are quite different from those of the $\mathrm{Er}^{3+}$ emissions at $525 \mathrm{~nm}, 551 \mathrm{~nm}, 667 \mathrm{~nm}, 806 \mathrm{~nm}$, and $1539 \mathrm{~nm}$, respectively. In particular, the PLE spectrum for $1539 \mathrm{~nm}$ NIR emission without the interference of STE luminescence shows two typical absorption bands rather than semiconductor-like band-to-band absorption (Fig. 2b). These two absorption bands can be assigned to $\mathrm{Bi}^{3+}: 6 \mathrm{~s}^{2} \rightarrow 6 \mathrm{~s} 6 \mathrm{p}\left({ }^{1} \mathrm{~S}_{0} \rightarrow{ }^{3} \mathrm{P}_{1},{ }^{1} \mathrm{~S}_{0} \rightarrow{ }^{1} \mathrm{P}_{1}\right)$ absorption transitions ${ }^{54}$. In fact, similar phenomena can be found in the PLE spectra of the other $\mathrm{Ln}^{3+}$ (Nd, Ho, Tm, and $\mathrm{Yb}$ ) NIR emissions (Fig. S12). These results indicate that the excitation of $\mathrm{Ln}^{3+}$ ions in $\mathrm{Cs}_{2} \mathrm{AgInCl}_{6}$ DP is mainly achieved via energy transfer from $\mathrm{Bi}^{3+}$ ions rather than the STE state (DP host). To verify this, we detected the PL decay curves for the STE emission of the Bi-doped and Bi/ Er codoped samples. The decay curves of the $\mathrm{Er}^{3+}$ emissions (Fig. 2c) exhibited typical parity-forbidden $4 \mathrm{f}-4 \mathrm{f}$ transitions with a long lifetime on a millisecond scale $\left(1.49 \mathrm{~ms}\right.$ for $\mathrm{Er}^{3+}:{ }^{4} \mathrm{~S}_{3 / 2} \rightarrow{ }^{4} \mathrm{I}_{15 / 2}, \quad 4.04 \mathrm{~ms}$ for $\mathrm{Er}^{3+}$ : ${ }^{4} \mathrm{~F}_{9 / 2} \rightarrow{ }^{4} \mathrm{I}_{15 / 2}$, and $30.43 \mathrm{~ms}$ for $\mathrm{Er}^{3+}:{ }^{4} \mathrm{I}_{13 / 2} \rightarrow{ }^{4} \mathrm{I}_{15 / 2}$ ), while the decay lifetime for STE emission was only $\sim 750 \mathrm{~ns}$ owing to the strong Jahn-Teller distortion-induced electron-hole recombination (Fig. 2d). Notably, the 

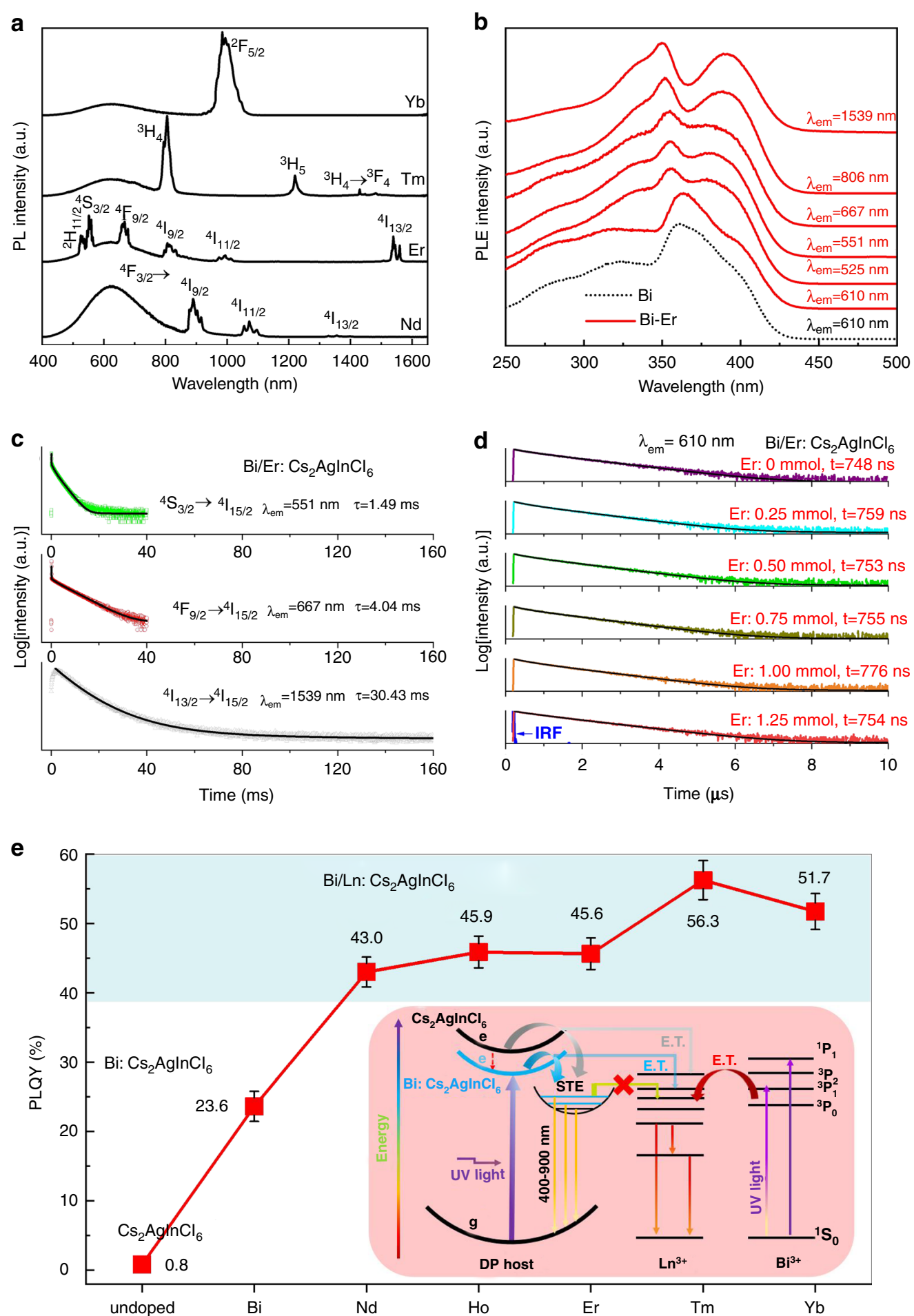

Fig. 2 Spectroscopic characterization and energy-transfer processes in $\mathbf{B i} / \mathbf{L n}: \mathrm{Cs}_{2} \mathbf{A g}_{\mathbf{g}} \mathbf{n C l} \mathbf{l}_{6} \mathbf{D P s}$. a PL spectra of the $B i / L n(L n=N b$, Er, Tm, and $\mathrm{Yb}): \mathrm{Cs}_{2} \mathrm{AgInCl}_{6}$ samples. b PLE spectra of the Bi:Cs $\mathrm{AgInCl}_{6}$ and $\mathrm{Bi} / \mathrm{Er}_{\mathrm{C}} \mathrm{Cs}_{2} \mathrm{AgInCl}_{6}$ samples obtained by monitoring different emitting wavelengths. PL decay curves obtained by monitoring (c) $\mathrm{Er}^{3+}$ emissions and (d) STE recombination in the Bi/Er:CS $\mathrm{AgInCl}_{6}$ samples. IRF represents the instrumental response function. e PLQYs for a series of the Bi/Ln:DPs. The inset shows the proposed energy-transfer mechanisms and emission processes involving both STE recombination and $\mathrm{Ln}^{3+} 4 \mathrm{f}-4 \mathrm{f}$ transitions 
decay lifetime for STE recombination shows no obvious change with increasing $\mathrm{Er}^{3+}$ doping content, indicating that there was no direct energy transfer from STE to the Ln dopants.

Herein, we propose a possible mechanism that describes the $\mathrm{Ln}^{3+}$ emissions in $\mathrm{Bi} / \mathrm{Ln}: \mathrm{Cs}_{2} \mathrm{AgInCl}_{6} \mathrm{DP}$, as demonstrated in Fig. 2e. $\mathrm{Cs}_{2} \mathrm{AgInCl}_{6} \mathrm{DP}$ is a direct bandgap semiconductor that undergoes a parity-allowed higherorder transition between the third valence band (VB) level and conductive-band minima $(\mathrm{CBM})$ at $\sim 4.8 \mathrm{eV}^{27,28}$. Interestingly, $\mathrm{Bi}^{3+}$ doping decreases the excitation energy to the UV region (extra-absorption energy state at $\sim 377 \mathrm{~nm}$, Fig. S3c) but no other PL peak, except STE emission (Fig. S2c), which might arise from contributions of $\mathrm{Bi}^{3+}$ orbitals in the band edges ${ }^{37,46,47}$. Based on theoretical calculations, $\mathrm{Bi}^{3+}$ incorporation is believed to modify the projected density of states at the band edges ${ }^{37}$, break the parity-forbidden transition of STE states ${ }^{50,55}$, and promote exciton localization ${ }^{30}$, giving rise to a new optical absorption channel at a lower energy (Fig. S3c) and promoting the PLQY of STE emission (Fig. S3a). The modified $\mathrm{VB} \rightarrow \mathrm{CB}$ excitation energy is then transferred to STE states responsible for visible broadband emission. Additionally, the $\mathrm{Bi}^{3+}$ ion has a $6 \mathrm{~s}^{2}$ outer-electron configuration with a ${ }^{1} \mathrm{~S}_{0}$ ground state, and optical transitions to the $6 s^{1} 6 p^{1}$ configuration lead to two intense absorptions assigned to the ${ }^{1} \mathrm{~S}_{0} \rightarrow{ }^{1} \mathrm{P}_{1}$ and ${ }^{1} \mathrm{~S}_{0} \rightarrow{ }^{3} \mathrm{P}_{1}$-allowed transitions (inset of Fig. 2e) ${ }^{54}$. These two absorption transitions can effectively transfer energy to the $\mathrm{Ln}^{3+}$ dopants in the DP host, which are de-excited by multiple light emissions with characteristic $4 \mathrm{f}-4 \mathrm{f}$ transitions in the NIR spectral range. In summary, both emissions from STE recombination and $\mathrm{Ln}^{3+} 4 \mathrm{f}-4 \mathrm{f}$ transitions are excitable by UV light, such as light from commercial UV chips, which are beneficial for their synergistic luminescence. Indeed, as demonstrated in Fig. 2e, the PLQY for $\mathrm{Cs}_{2} \mathrm{AgInCl}_{6}$ DP is below $1 \%, \mathrm{Bi}^{3+}$ doping promotes the value up to $\sim 24 \%$ for efficient UV excitation, and $\mathrm{Ln}^{3+}$ codoping further increases the PLQY to $43 \sim 56 \%$ owing to the superposition of the additional $\mathrm{Ln}^{3+}$ emissions. Notably, the $\mathrm{Cs}_{2} \mathrm{AgInCl}_{6}$ DP reported by Luo et al. has been codoped with $\mathrm{Na}^{+}$ions, which can significantly improve the PLQY up to $~ 90 \%$ by breaking the parityforbidden transition of STE-radiative recombination ${ }^{30}$. Unfortunately, the doping of $\mathrm{Na}^{+}$in this sample is detrimental to the incorporation of $\mathrm{Ln}^{3+}$ into the $\mathrm{Cs}_{2} \mathrm{AgInCl}_{6}$ lattice. Therefore, only the $\mathrm{Cs}_{2} \mathrm{AgInCl}_{6} \mathrm{DP}$ without $\mathrm{Na}^{+}$ dopant was used as the host for $\mathrm{Ln}^{3+}$ doping.

To achieve ultrabroadband luminescence in the visible-NIR spectral range, it is necessary to dope multiple $\mathrm{Ln}^{3+}$ activators into a sole DP host. First, the multi-doped $\mathrm{Nd}^{3+}, \mathrm{Yb}^{3+}, \mathrm{Er}^{3+}$, and $\mathrm{Tm}^{3+}$ DP samples were prepared. Compared with those of the single-doped samples, the NIR emission intensities of all the $\operatorname{Ln}^{3+} 4 \mathrm{f}-4 \mathrm{f}$ transitions in the multidoped sample decreased significantly (Fig. 3a). Indeed, the PLQY of the multidoped sample decreased to $13 \%$ (Fig. 3b). This PL coquenching phenomenon is attributed to detrimental energy transfers and migrations among $\mathrm{Nd}^{3+}$, $\mathrm{Yb}^{3+}, \mathrm{Er}^{3+}$, and $\mathrm{Tm}^{3+}$ dopants due to their well-matched and abundant multiplets ${ }^{56}$. As shown in Fig. 3c, the energy levels of $\mathrm{Nd}, \mathrm{Er}$, and $\mathrm{Tm}$ ions in the red, yellow, and blue regions are well matched, enabling energy migration among them to defect sites in the multidoped samples and finally leading to PL quenching. In addition, taking $\mathrm{Ln}^{3+}$ couples (such as $\mathrm{Nd}$ and $\mathrm{Yb}, \mathrm{Nd}$ and $\mathrm{Tm}, \mathrm{Nd}$ and $\mathrm{Er}$, and $\mathrm{Er}$ and $\mathrm{Tm})$ as typical examples, several energy transfer and crossrelaxation processes among $\mathrm{Ln}^{3+}$ ions are responsible for the energy loss via nonradiative relaxation (Fig. S13). All these detrimental energy-transfer processes finally quench the $\mathrm{Ln}^{3+}$ emissions in the multidoped samples. To address this challenge, we herein provide a strategy to spatially confine different $\mathrm{Ln}^{3+}$ dopants in a heterogeneous architecture (Fig. 3d), which involves the codispersion of $\mathrm{Nd}$ : $\mathrm{Cs}_{2} \mathrm{AgInCl}_{6}, \mathrm{Yb} / \mathrm{Er}: \mathrm{Cs}_{2} \mathrm{AgInCl}_{6}$, and $\mathrm{Yb} / \mathrm{Tm}: \mathrm{Cs}_{2} \mathrm{AgInCl}_{6}$ DPs into an inorganic glass matrix through a lowtemperature cosintering technique ${ }^{57,58}$ to form a DP-inglass (DiG) composite. Herein, the heterogeneous DiG architecture is not a multilayered structure but a monolithic composite with a size of $1 \times 1 \mathrm{~cm}^{2}$ and a thickness of $75 \mu \mathrm{m}$. This method enables the effective avoidance of unwanted energy interactions among $\mathrm{Ln}^{3+}$ ions and produces intense $\mathrm{Ln}^{3+}$ NIR emissions for the separate doping of $\mathrm{Nd}$, Er, and Tm ions in DPs. As shown in Fig. S13f-h, the decay lifetimes of the typical $\mathrm{Nd}^{3+}:{ }^{4} \mathrm{~F}_{3 / 2} \rightarrow{ }^{4} \mathrm{I}_{9 / 2}, \mathrm{Er}^{3+}:{ }^{4} \mathrm{~F}_{9 / 2} \rightarrow{ }^{4} \mathrm{I}_{15 / 2}$, and $\mathrm{Tm}^{3+}:{ }^{3} \mathrm{H}_{4} \rightarrow{ }^{3} \mathrm{H}_{6}$ transitions in the $\mathrm{Nd} / \mathrm{Yb} / \mathrm{Er} / \mathrm{Tm}$ multidoped sample are far shorter than those in the Nd-, Yb/Er-, and $\mathrm{Yb} / \mathrm{Tm}$-doped samples. Importantly, the decay lifetimes recover after the DiG sample is formed, confirming the efficient inhibition of detrimental energy transfer among the various $\mathrm{Ln}^{3+}$-emitting centers.

The thermal stability of the $\mathrm{Ln}: \mathrm{Cs}_{2} \mathrm{AgInCl}_{6}$ sample was characterized by differential thermal analysis (DTA) and thermogravimetric (TG) analysis (Fig. 3e). Both the DTA and TG curves show that the Ln: $\mathrm{Cs}_{2} \mathrm{AgInCl}_{6}$ sample was stable below $500{ }^{\circ} \mathrm{C}$, and further increasing the temperature led to the gradual decomposition of the DP (inset of Fig. 3e, Fig. S14). In this case, it is important to choose an appropriate low-melting inorganic glass to successfully fabricate DiG composites. Herein, a sodium silicate glass with the composition of $\mathrm{SiO}_{2}-\mathrm{Na}_{2} \mathrm{O}-\mathrm{K}_{2} \mathrm{O}-\mathrm{ZnO}$ was selected because of its excellent moisture resistance and low melting temperature $\left(500^{\circ} \mathrm{C}\right)$. As illustrated in Fig. $\mathrm{S} 15$, the viscous $\mathrm{Ln}: \mathrm{Cs}_{2} \mathrm{AgInCl}_{6}$ ink paste was first prepared by admixing $\mathrm{Ln}: \mathrm{Cs}_{2} \mathrm{AgInCl}_{6}(\mathrm{Ln}=\mathrm{Nd}, \mathrm{Yb} / \mathrm{Er}$, and $\mathrm{Yb} / \mathrm{Tm})$ phosphors, glass powders and organic vehicles via thorough grinding. Second, the ink paste was spined on a single-crystal sapphire (SA) substrate with high thermal conductivity $\left(\sim 30 \mathrm{~W} \mathrm{~m}^{-1} \mathrm{~K}^{-1}\right)$ and then placed on 


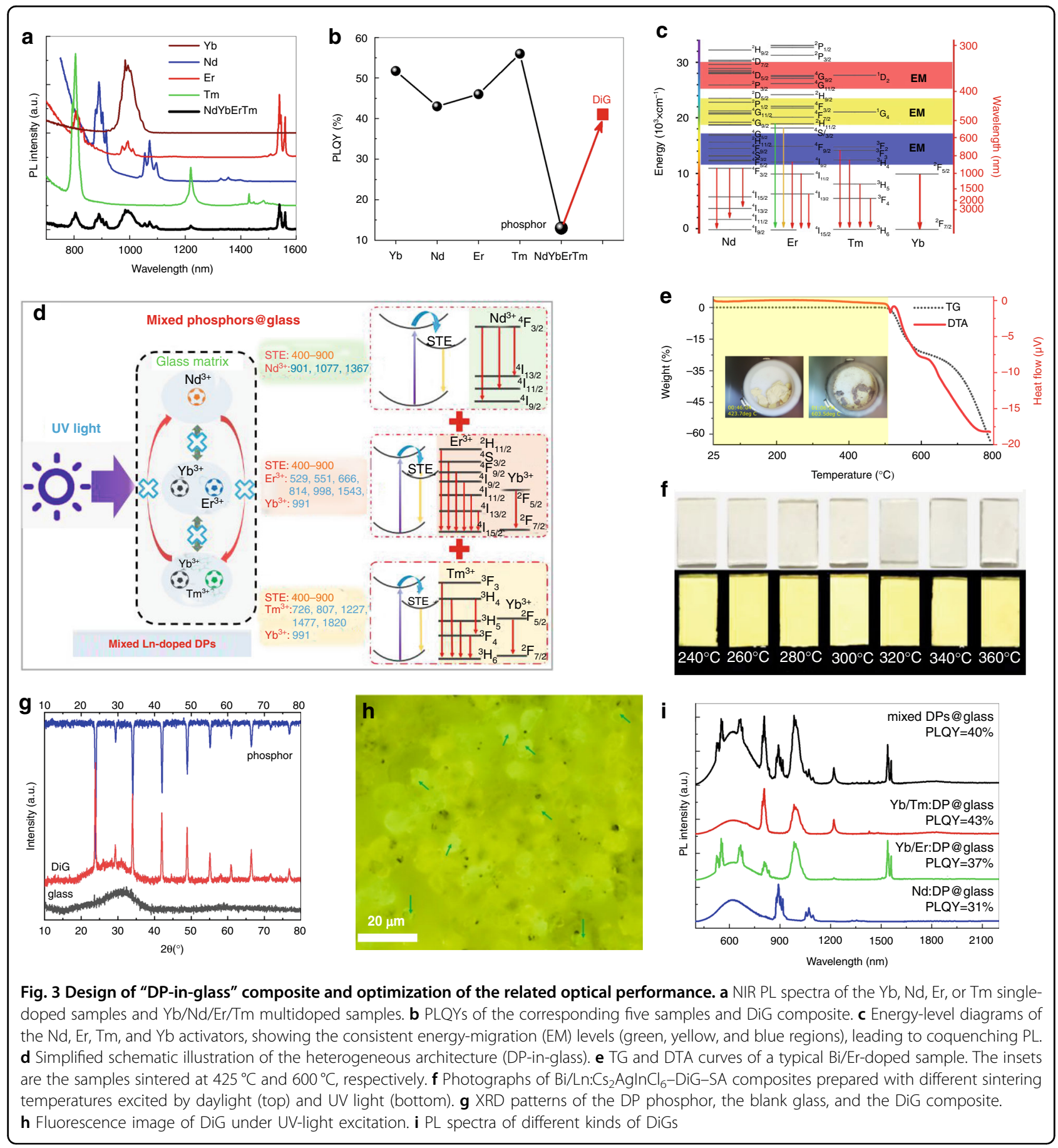

a heating table for drying. Finally, it was sintered in a muffle furnace at $240-360^{\circ} \mathrm{C}$ for a certain duration to obtain the $\mathrm{Bi} / \mathrm{Ln}: \mathrm{Cs}_{2} \mathrm{AgInCl}_{6}-\mathrm{DiG}-\mathrm{SA}$ composite (Fig. 3f). The use of an SA substrate is beneficial for improving the thermal conductivity of the composite film, and the optimized synthesis temperature/time is $300{ }^{\circ} \mathrm{C} / 15 \mathrm{~min}$ (Fig. S16). XRD patterns confirm that the added Ln: $\mathrm{Cs}_{2} \mathrm{AgInCl}_{6}$ DPs were retained in the glass without obvious decomposition (Fig. 3g). Fluorescence images of the composite film (Fig. 3h, Fig. S17) under UV-light excitation show the distribution of luminescent $\mathrm{Bi} / \mathrm{Ln}$ : $\mathrm{Cs}_{2} \mathrm{AgInCl}_{6}$ DP particles inside the nonluminescent glass matrix. Notably, the $\mathrm{Bi} / \mathrm{Yb} / \mathrm{Er}: \mathrm{Cs}_{2} \mathrm{AgInCl}_{6}$ microcrystals can be well distinguished from the $\mathrm{Bi} / \mathrm{Nd}: \mathrm{DP}$ and $\mathrm{Bi} / \mathrm{Yb} /$ Tm:DP microcrystals for their light-green luminescence (indicated by the arrows) owing to the superimposed $\mathrm{Er}^{3+}$ emissions on the STE broadband emission (Fig. S17). As shown in Fig. 3i, the PLQY of the mixed multiple Bi/Ln: 

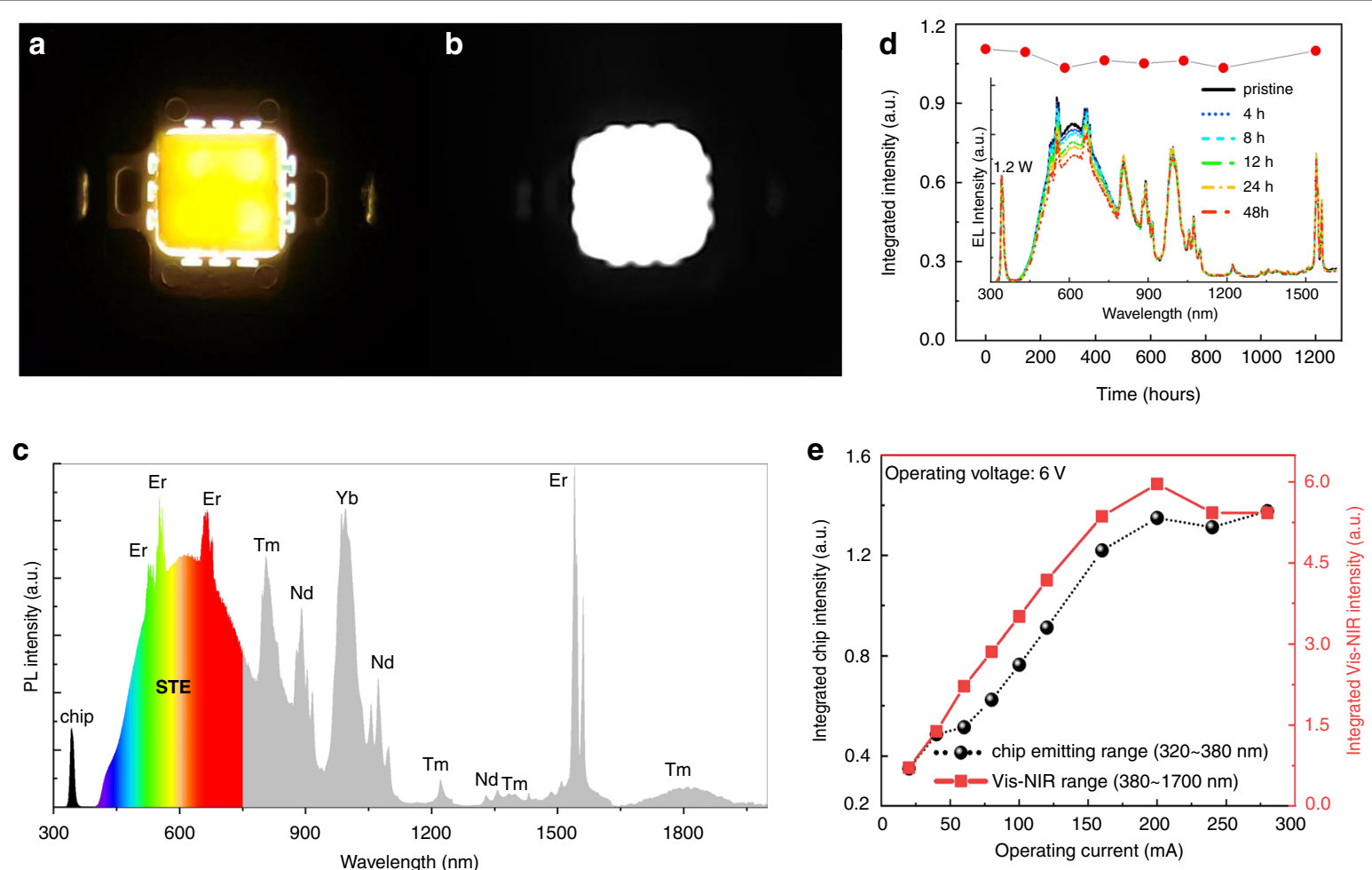

Fig. 4 Construction of ultrabroadband LED based on Bi/Ln:DP@glass composite. Photographs of the constructed Bi/Ln:DP@glass-based LED device with an operating current of $200 \mathrm{~mA}$ taken by (a) a visible-light camera and (b) NIR camera. c PL spectrum of the LED device. $\mathbf{d}$ Dependence of the PL intensity of the LED on the exposure time in air. The inset shows the PL spectra of LEDs continuously operating for $48 \mathrm{~h}$. $\mathbf{e}$ Dependence of the UV-emitting intensity of the chip and Vis-NIR-emitting intensity of DiP on the operating current from 20 to $350 \mathrm{~mA}$

DPs in glass is comparable to those of the only one type of DP-embedded glasses, confirming the successful inhibition of adverse energy transfer by isolating different $\mathrm{Ln}^{3+}$ dopants in diverse DPs. As a consequence, the PLQY $(\sim 40 \%)$ of the three types of DP-(Nd:DP, Yb/Er:DP, and $\mathrm{Yb} / \mathrm{Er}: \mathrm{DP})$ embedded glass is much higher than that of the $\mathrm{Nd} / \mathrm{Yb} / \mathrm{Er} / \mathrm{Tm}$ multidoped DP phosphor ( 13\%, Fig. 3b).

In a further work, a light-emitting diode (LED) was fabricated by coupling the prepared DiG with a commercial $350 \mathrm{~nm}$ UV chip, which can produce brightyellow light visible to the naked eye (Fig. 4a) and intense NIR light observable by a night-vision camera (Fig. 4b). The PL spectra of the operating device show one narrow UV emission assigned to the chip, a broadband visible emission assigned to STE recombination, and many narrowband emissions ascribed to the $\mathrm{Er}^{3+}, \mathrm{Nd}^{3+}, \mathrm{Yb}^{3+}$, and $\mathrm{Tm}^{3+} 4 \mathrm{f}-4 \mathrm{f}$ transitions (Fig. 4c), covering the ultrabroad spectral region from 400 to $2000 \mathrm{~nm}$ with a full width at half-maximum (FWHM) of $\sim 365 \mathrm{~nm}$. The NIR emission located at $\sim 1820 \mathrm{~nm}$ with a decay lifetime of $6.69 \mathrm{~ms}$ is assigned to the $\mathrm{Tm}^{3+}:{ }^{3} \mathrm{~F}_{4} \rightarrow{ }^{3} \mathrm{H}_{6}$ transition (Fig. S18). To the best of our knowledge, this is the first report on an ultrabroadband light source based on the combination of $\mathrm{Ln}^{3+}$ dopants and DP. Importantly, the
PL intensity remained almost unchanged after the device was exposed to air for $1200 \mathrm{~h}$ (Fig. 4d), confirming its super long-term stability. In fact, the DiG composite is stable after exposure to air for 180 days (Fig. S19). Moreover, after continuous operation for $48 \mathrm{~h}$, only slight thermal quenching for STE emission occurred, and no obvious changes in the $\mathrm{Ln}^{3+}$ emissions were observed in the PL spectra (inset of Fig. 4d). The STE emission is sensitive to temperature (Fig. S20a), and the increased temperature of the UC chip during operation leads to a certain degree of PL quenching. Additionally, the $4 \mathrm{f}$ orbitals of the $\mathrm{Ln}^{3+}$ ions are shielded from the surroundings by the filled $5 s^{2}$ and $5 p^{6}$ orbitals. Therefore, the influence of temperature on the optical transitions within the $4 \mathrm{f}^{\mathrm{n}}$ configuration is small since there is no crossover point between the excited state and the ground state in the $\mathrm{Ln}^{3+}$ configuration ${ }^{13}$. In this case, no obvious change in the $\mathrm{Ln}^{3+}$ PL intensity was detected with increasing temperature, while PL quenching of STE was observed since exciton recombination is highly sensitive to temperature (Fig. S20b). Fortunately, the temperature of the constructed $\mathrm{u}$-LED with long-term operation is stable (remained below $30^{\circ} \mathrm{C}$ ) owing to the use of a cooling fan (Fig. S21). Therefore, thermal quenching only 
subtly impacted the u-LED performance after several weeks. The excellent stability of the device is ascribed to the effective protection of the inorganic glass matrix for the $\mathrm{Bi} / \mathrm{Ln}: \mathrm{Cs}_{2} \mathrm{AgInCl}_{6}$ color converters, which inhibits the decomposition of and damage to the DPs upon exposure to external stimuli. As shown in Fig. 4e, both the UV and NIR emissions increased monotonically with increasing operating current from $20 \mathrm{~mA}$ to $200 \mathrm{~mA}$ and tended to be stable for higher input currents owing to the saturation of the commercial $350 \mathrm{~nm}$ UV chip.

Finally, we demonstrate the promising applications of this compact ultrabroadband LED (u-LED) in nondestructive spectroscopic analysis and multifunctional lighting. The absorption spectra of some substances, such as water, ethyl alcohol (EtOH), plum, tomato, grape, and white/yellow egg, were measured using the $\mathrm{u}$-LED as the light source. The sample was placed inside an integrating sphere equipped with the u-LED and a fiber-coupled spectrometer (Fig. 5a). The absorption spectrum of the sample was obtained by subtracting the emission spectrum of the $\mathrm{u}$-LED recorded without the sample from that recorded with the sample. As shown in Fig. 5b, the absorption of water and $\mathrm{EtOH}$ in the visible spectral region is negligible, and several NIR-absorption peaks located at $810 \mathrm{~nm}, 994 \mathrm{~nm}, 1220 \mathrm{~nm}$, and $1545 \mathrm{~nm}$ are observed. In comparison, the fruits and eggs showed strong absorption in the visible spectral range in addition to NIR-absorption peaks; these absorption signals were similar to those observed in water and EtOH (Fig. 5c). The visible absorption intensity of dark-red plum, red tomato, and green grape decreases in sequence, which is probably due to the relationship between the color of fruits and the absorption of visible light by phytochromes. A similar phenomenon can be observed for eggs with different apparent colors (white and red), where the visible absorption of white eggs is remarkably lower than that of red eggs. The exact origin of absorption is not discussed, and quantitative analysis is not performed in the present work due to its complexity and because it is beyond the scope of this research. Figure 5d and Fig. S22 present photographs of fruits and palms taken via different cameras (visible camera and NIR camera). No image can be captured by either camera when the u-LED is off (middle of Fig. 5d). In contrast, when the u-LED lamp is lightened, the colorful image (left of Fig. 5d, Fig. S22a) and blackand-white image (right of Fig. 5d, Fig. S22b) are easily detected by the visible camera and NIR camera, respectively. This kind of dual-modal lighting based on u-LED is ascribed to its broadband emissions covering both visible and NIR spectral regions. In addition, when the light from the $\mathrm{u}$-LED is passed through the palm and fingers, the venous blood vessels in the palm and fingers are discerned by the NIR camera (Fig. 5e, Fig. S22) owing to the loss of NIR light absorbed by the chromophores in the blood.

\section{Conclusions}

In summary, a family of $\mathrm{Ln}^{3+}$ ions and $\mathrm{Bi}^{3+}$ ions was successfully doped into $\mathrm{Cs}_{2} \mathrm{AgInCl}_{6}$ DP microcrystals prepared by a modified coprecipitation method. $\mathrm{Bi}^{3+}$ ions were easily incorporated into DPs by substituting ${\operatorname{~}{ }^{3+}}^{3+}$, while $\mathrm{Ln}^{3+}$ doping resulted in a saturation concentration of $\sim 2.5 \mathrm{~mol} \%$. $\mathrm{Bi}^{3+}$ doping can decrease the excitation energy to the UV region (330-400 nm) for STE recombination and significantly promote the PLQY from $\sim 1 \%$ to $\sim 25 \%$ owing to the $\mathrm{Bi}^{3+}$-doping-induced modification of the band-edge structure of $\mathrm{Cs}_{2} \mathrm{AgInCl}_{6} \mathrm{DP}$. Importantly, $\mathrm{Ln}^{3+}$ codoping can further increase the PLQY to $43 \sim 56 \%$ owing to the superimposition of the additional $\mathrm{Ln}^{3+}$ emissions on the broadband STE luminescence. A series of spectroscopic characterizations evidence the different energy-transfer channels for STE emission and $\mathrm{Ln}^{3+} 4 \mathrm{f}-4 \mathrm{f}$ emissions, where the former is attributed to energy transfer from band-edge to STE state and the latter is due to energy transfer from $\mathrm{Bi}^{3+}$ in the $6 \mathrm{~s}^{1} 6 \mathrm{p}^{1}$ state to the $\mathrm{Ln}^{3+}$ multiplets. In this case, $\mathrm{Nd} / \mathrm{Yb} / \mathrm{Er} / \mathrm{Tm}$ multidoping in Bi:DP can produce ultrabroadband luminescence covering the Vis and NIR spectral regions. Furthermore, a DiG composite was fabricated by dispersing diverse $\mathrm{Nd}$ : $\mathrm{DP}, \mathrm{Yb} / \mathrm{Er}$ :DP, and $\mathrm{Yb} / \mathrm{TmDP}$ in an inorganic glass matrix to spatially confine the various $\mathrm{Ln}^{3+}$ dopants, which is beneficial for inhibiting the coquenching PL for multiple $\mathrm{Ln}^{3+}$ ions in a single DP host. Finally, the DiP-based light source was designed; it exhibited a commercial UV chip with excitable ultrabroadband $(400 \sim 2000 \mathrm{~nm})$ electroluminescence. This compact $\mathrm{u}$-LED has a low cost, is easy to manufacture, is nontoxic, exhibits excellent optoelectronic performance, and is stable; therefore, it provides practicality, commercialization, and industrialization in multifunctional lighting and nondestructive spectral analysis.

\section{Methods \\ Chemicals}

Indium(III) trichloride $\left(\mathrm{InCl}_{3}\right.$, Shanghai Macklin Chem. Co., LTD., 99.9\%), bismuth trichloride $\left(\mathrm{BiCl}_{3}\right.$, Macklin, 99.9\%), silver chloride ( $\mathrm{AgCl}$, Macklin, 99.5\%), hydrochloric acid ( $\mathrm{HCl}$, Hushi, 99.99\%), cesium chloride $(\mathrm{CsCl}$, Macklin, 99.9\%), and lanthanide(III) chloride hexahydrate $\left(\mathrm{LnCl}_{3} \cdot 6 \mathrm{H}_{2} \mathrm{O}, \mathrm{Ln}=\mathrm{La}-\mathrm{Lu}\right.$, Beijing HWRK Chem. Co., LTD., 99.99\%). All of the chemicals were used without further purification.

\section{Synthesis of $\mathrm{Bi}^{3+}$-doped $\mathrm{Cs}_{2} \mathrm{AgInCl}_{6}$}

Before the reaction, a shaded and heat-resistant glass bottle was prepared in advance to prevent the oxidation of silver chloride (movie 1). First, different amounts of $\mathrm{BiCl}_{3}$ $(0,0.003,0.006,0.012,0.024,0.036,0.048,0.060$, and $0.100 \mathrm{mmol}), 0.25 \mathrm{mmol}$ of $\mathrm{InCl}_{3}, 0.25 \mathrm{mmol}$ of $\mathrm{AgCl}$, and $4 \mathrm{mmol}$ of $12 \mathrm{M} \mathrm{HCl}$ were added to an $8 \mathrm{~mL}$ glass bottle. 

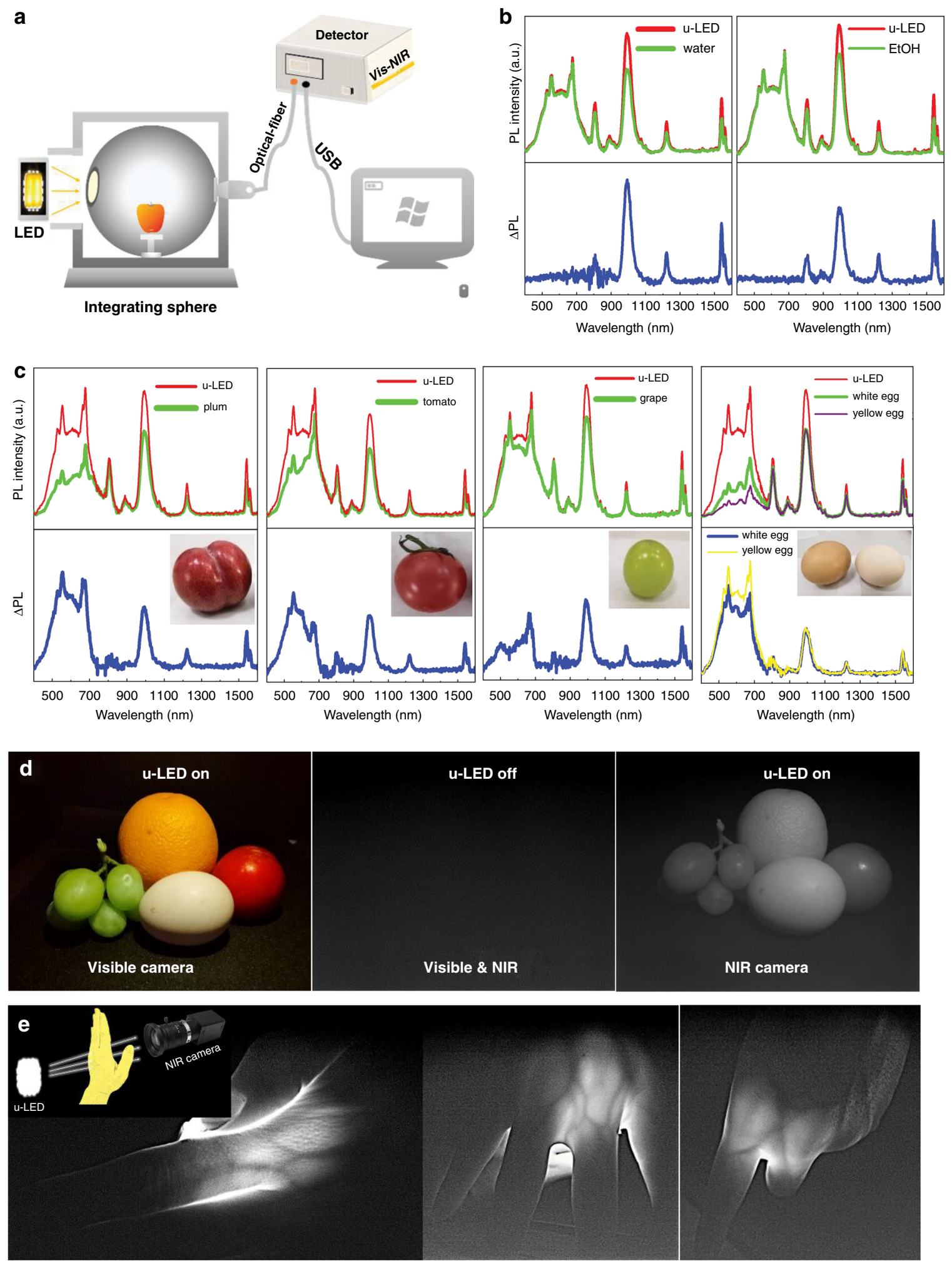

Fig. 5 Application demonstration of Bi/Ln:DP-based ultrabroadband LED. a Schematic diagram of the experimental setup for measuring absorption. PL spectra with and without the measured substance inside the integrated sphere using u-LED as the light source: (b) water and EtOH, (c) plum, tomato, grape, and eggs. $\triangle \mathrm{PL}$ is defined as PL(u-LED) - PL(u-LED + substance). $\mathbf{d}$ Photos of fruits with and without u-LED irradiation recorded by visible and NIR cameras. e Photos of palm and finger after transillumination of NIR light from u-LED 
Second, the glass bottle was placed in an oil bath pan at $100^{\circ} \mathrm{C}$ and stirred vigorously, until all the powders in the reaction mixture were completely dissolved. Third, $0.5 \mathrm{mmol} \mathrm{CsCl}$ was dissolved in $1 \mathrm{~mL}$ of $12 \mathrm{M} \mathrm{HCl}$ and swiftly injected into the glass bottle to produce the products. The reaction continued for another $20 \mathrm{~min}$ to ensure that it was complete. Then, the glass bottle was magnetically stirred at room temperature for $10 \mathrm{~min}$. The crude microcrystalline solution was centrifuged at $10000 \mathrm{rpm}$ for $5 \mathrm{~min}$, and the supernatant was discarded. The residual sediment was washed twice with ethanol, and the solution was then centrifuged at $10000 \mathrm{rpm}$ for $10 \mathrm{~min}$. Finally, the precipitates were dried at $80^{\circ} \mathrm{C}$ in a drying oven overnight and then stored.

\section{Synthesis of $\mathrm{Bi} / \mathrm{Er}$ codoped $\mathrm{Cs}_{2} \mathrm{Ag} \mathrm{InCl}_{6}$}

The synthesis process was similar to that of $\mathrm{Bi}^{3+}$-doped $\mathrm{Cs}_{2} \mathrm{AgInCl}_{6}$. The only difference was that the $\mathrm{BiCl}_{3}$ content was fixed at $0.048 \mathrm{mmol}$, and different amounts of $\mathrm{ErCl}_{3} \quad(0, \quad 0.25, \quad 0.50, \quad 0.75, \quad 1.00$, and $1.25 \mathrm{mmol})$ were added.

\section{Synthesis of Bi/Ln ( $\mathrm{Ln}=\mathrm{La}-\mathrm{Lu}$ ) codoped $\mathrm{Cs}_{2} \mathrm{AgInCl}_{6}$}

The synthesis process was similar to that of $\mathrm{Bi}^{3+}$-doped $\mathrm{Cs}_{2} \mathrm{AgInCl}_{6}$. The only difference was that the $\mathrm{BiCl}_{3}$ and $\mathrm{LnCl}_{3}$ contents were fixed at $0.048 \mathrm{mmol}$ and $0.75 \mathrm{mmol}$, respectively.

\section{Synthesis of $\mathrm{Bi} / \mathrm{Yb} / \mathrm{Ln}(\mathrm{Ln}=\mathrm{Er}, \mathrm{Tm}$, or Ho) triple-doped $\mathrm{Cs}_{2} \mathrm{AgInCl}_{6}$}

The synthesis process was similar to that of $\mathrm{Bi}^{3+}$-doped $\mathrm{Cs}_{2} \mathrm{AgInCl}_{6}$. The only difference was that the $\mathrm{BiCl}_{3}$, $\mathrm{YbCl}_{3}$, and $\mathrm{LnCl}_{3}\left(\mathrm{Ln}=\mathrm{Er}^{3+}, \mathrm{Tm}^{3+}\right.$ or $\left.\mathrm{Ho}^{3+}\right)$ contents were fixed at $0.048 \mathrm{mmol}, 0.75 \mathrm{mmol}$ and $0.75 \mathrm{mmol}$, respectively.

\section{Synthesis of $\mathrm{Bi} / \mathrm{Nd} / \mathrm{Yb} / \mathrm{Er} / \mathrm{Tm}$ multidoped $\mathrm{Cs}_{2} \mathrm{AgInCl}_{6}$}

The synthesis process was similar to that of $\mathrm{Bi}^{3+}$-doped $\mathrm{Cs}_{2} \mathrm{AgInCl}_{6}$. The only difference was that the $\mathrm{BiCl}_{3}$ content was fixed at $0.048 \mathrm{mmol}$ and all $\mathrm{LnCl}_{3}$ contents were fixed at $0.75 \mathrm{mmol}$.

\section{Fabrication of $\mathrm{Bi} / \mathrm{Ln}: \mathrm{Cs}_{2} \mathrm{AgInCl}_{6} @ g$ lass}

First, diethylene glycol monobutyl ether acetate (DBAC), ethyl cellulose (EC), and terpineol precursors were added to a glass bottle. Then, the slurry was heated to $80^{\circ} \mathrm{C}$ for at least $50 \mathrm{~min}$ to fully react. In addition, the inorganic glass frits with compositions of $\mathrm{SiO}_{2}-\mathrm{Na}_{2} \mathrm{O}-\mathrm{K}_{2} \mathrm{O}-\mathrm{ZnO}$ and the $\mathrm{Bi}$-/Ln-doped DP phosphors were ground with a small amount of the above-mentioned slurry for $20 \mathrm{~min}$ and then spined on the single-crystal sapphire. Finally, the composite film was sintered in a muffle furnace at $240-360^{\circ} \mathrm{C}$ for $15 / 30 \mathrm{~min}$ to obtain DP-in-glass (DiG). Notably, for ultrabroadband LED applications, DiG is a monolithic composite, where $\mathrm{Nd}: \mathrm{Cs}_{2} \mathrm{AgInCl}_{6}, \mathrm{Yb} / \mathrm{Er}$ : $\mathrm{Cs}_{2} \mathrm{AgInCl}_{6}$, and $\mathrm{Yb} / \mathrm{Tm}: \mathrm{Cs}_{2} \mathrm{AgInCl}_{6}$ DPs are codispersed inside an inorganic glass matrix.

\section{Fabrication of DiG-based LEDs}

The compact ultrabroadband-emitting light-emitting diode ( $\mathrm{u}-\mathrm{LED}$ ) was constructed by coupling the prepared monolithic DiG layer with a commercial $350 \mathrm{~nm}$ UV chip by placing the DiG on the surface of the UV chip. A cooling fan was adhered to the back of the UV chip to reduce the thermal accumulation upon operation. The opaque silica gels were filled around the edges between DiG and the UV chip to prevent the leakage of UV light.

\section{Characterizations}

$\mathrm{X}$-ray diffraction (XRD) analysis was carried out to identify $\mathrm{Bi} / \mathrm{Ln}: \mathrm{Cs}_{2} \mathrm{AgInCl}_{6}$ crystalline-phase structures using a Bruker D8 Advance X-ray powder diffractometer with $\mathrm{Cu} \mathrm{K}_{\alpha}$ radiation $(\lambda=0.154 \mathrm{~nm})$ operating at $40 \mathrm{kV}$. The actual chemical compositions were measured by inductively coupled plasma-mass spectrometry (ICP-MS) using a PerkinsElmer Optima 3300DV spectrometer. The microstructures of the samples were characterized by scanning electron microscopy (SEM) equipped with an energy-dispersive $\mathrm{X}$ ray (EDX) spectroscopy system and were visualized via fluorescence images using optical microscopy (Nikon, Eclipse, Ti2) coupled with a spectrofluorometer. The elemental analysis of $\mathrm{Bi} / \mathrm{Ln}: \mathrm{Cs}_{2} \mathrm{AgInCl}_{6}$ was performed by $\mathrm{X}$-ray photoelectron spectroscopy (XPS) using a VG Scientific ESCA Lab Mark II spectrometer equipped with two ultrahigh vacuum-6 (UHV) chambers. All the binding energies were referenced to the $\mathrm{C}_{1 \mathrm{~s}}$ peak of the adventitious carbon on the surface at $284.8 \mathrm{eV} .{ }^{133} \mathrm{Cs}$ and ${ }^{115}$ In magicangle-spinning nuclear magnetic resonance (MAS-NMR) spectra were recorded using Bruker ADVANCE III HD 400 spectrometers. The diffuse-reflectance spectra were recorded on a spectrophotometer (Lambda900, PerkinElmer) with a resolution of $1 \mathrm{~nm}$. Thermogravimetric analyses (TGA) were conducted on a Netzsch STA449C thermal analysis system under a $\mathrm{N}_{2}$ flow with a heating rate of $10^{\circ} \mathrm{C} \mathrm{min}^{-1}$. Photoluminescence (PL) spectra, PL-excitation (PLE) spectra and decay curves were recorded on an Edinburgh Instruments FLS1000 spectrofluorometer equipped with a continuous xenon lamp ( $450 \mathrm{~W})$, a pulsed flash lamp, and a $375 \mathrm{~nm}$ picosecond pulsed laser. Middle-infrared (MIR) PL emission spectra and decay curves were measured with a customized UV to mid-infrared steady-state and phosphorescence-lifetime spectrometer (FSP920-C, Edinburgh) equipped with a tuneable midband optical parametric oscillator pulsed laser as the excitation source $\left(210-2400 \mathrm{~nm}, 10 \mathrm{~Hz}\right.$, pulse width $\leq 5 \mathrm{~ns}$, Opolette $\mathrm{O}^{\mathrm{TM}}$ HE355UV, OPOTEK). The absolute photoluminescence quantum yields (PLQYs) of the samples were obtained by employing a standard barium sulfate-coated integrating 
sphere $(150 \mathrm{~mm}$ in diameter, Edinburgh) as the sample chamber that was mounted on the FLS1000 spectrometer with the entry and output port of the sphere located at a $90^{\circ}$ angle from each other in the plane of the spectrometer. A standard tungsten lamp was used to correct the optical response of the instrument. All the spectral data were collected at RT and corrected for the spectral response of both the spectrometer and the integrating sphere. PLQY $(450-1600 \mathrm{~nm})$ of Ln:DP covering the Vis-NIR broad spectral range equals the sum of $\operatorname{PLQY}_{(450-930 \mathrm{~nm})}$ and $\operatorname{PLQY}_{(930-1600 \mathrm{~nm})}$. PLQY $_{(930-1600 \mathrm{~nm})}$ was determined by the expression PLQY $(650-930 \mathrm{~nm}) \times \mathrm{I}_{(930-1600 \mathrm{~nm})} / \mathrm{I}_{(650-930 \mathrm{~nm})}$. Note that the integral intensities for both $\mathrm{I}_{(930-1600 \mathrm{~nm})}$ and $\mathrm{I}_{(650-930 \mathrm{~nm})}$ here come from the same near-infrared spectra (620-1650 nm). PL spectra of the UV LED chip and the fabricated u-LED were measured using a Keithley 2400 source and an integrating sphere equipped with an FLS1000 spectrofluorometer.

\section{Acknowledgements}

This research was supported by the National Natural Science Foundation of China (51972060, U1805252, and 22135008), the Fujian Science \& Technology Innovation Laboratory for Optoelectronic Information (2021ZZ126), and the Natural Science Foundation of Fujian Province (2020J02017, 2021 L3024).

\section{Author details}

'College of Physics and Energy, Fujian Normal University, Fujian Provincial Key Laboratory of Quantum Manipulation and New Energy Materials, Fuzhou 350117, China. ${ }^{2}$ Fujian Science \& Technology Innovation Laboratory for Optoelectronic Information, Fuzhou 350116, China. ${ }^{3}$ CAS Key Laboratory of Design and Assembly of Functional Nanostructures, Fujian Key Laboratory of Nanomaterials and State Key Laboratory of Structural Chemistry, Fujian Institute of Research on the Structure of Matter, Chinese Academy of Sciences, Fuzhou, Fujian 350002, China. ${ }^{4}$ Fujian Provincial Collaborative Innovation Center for Advanced High-Field Superconducting Materials and Engineering, Fuzhou 350117, China. ${ }^{5}$ Fujian Provincial Engineering Technology Research Center of Solar Energy Conversion and Energy Storage, Fuzhou 350117, China. ${ }^{6}$ College of Chemistry, Fuzhou University, Fuzhou 350116, China

\section{Author contributions}

D. C. and X. C. conceived, designed and supervised the overall project. S. J. and R. L. conducted the experiments, and S. J. and R. L. wrote the paper. H. H. and N. J. performed optical spectroscopic characterizations. All the authors discussed the results and commented on the paper.

\section{Conflict of interest}

The authors declare that they have no competing interest.

Supplementary information The online version contains supplementary material available at https://doi.org/10.1038/s41377-022-00739-2.

Received: 30 November 2021 Revised: 10 February 2022 Accepted: 13 February 2022

Published online: 08 March 2022

\section{References}

1. Rizzo, A. et al. Ultra-broadband interleaver for extreme wavelength scaling in silicon photonic links. IEEE Photonics Technol. Lett. 33, 55-58 (2021).

2. Hayashi, D. et al. A broadband LED source in visible to short-wave-infrared wavelengths for spectral tumor diagnostics. Appl. Phys. Lett. 110, 233701 (2017).
3. Joos, J. J. et al. Broadband infrared LEDs based on europium-to-terbium charge transfer luminescence. Nat. Commun. 11, 3647 (2020).

4. Tikhomirov, V. K. et al. Broadband telecommunication wavelength emission in $\mathrm{Yb}^{3+}-\mathrm{Er}^{3+}-\mathrm{Tm}^{3+}$ co-doped nano-glass-ceramics. Opt. Express 15, 9535-9540 (2007).

5. Zhou, S. F. et al. Multifunctional bismuth-doped nanoporous silica glass: from blue-green, orange, red, and white light sources to ultra-broadband infrared amplifiers. Adv. Funct. Mater. 18, 1407-1413 (2008).

6. Jones, D. J. et al. Carrier-envelope phase control of femtosecond mode-locked lasers and direct optical frequency synthesis. Science 288, 635-639 (2000).

7. Rajendran, V. et al. Ultra-broadband phosphors converted near-infrared light emitting diode with efficient radiant Power for spectroscopy applications. ACS Photonics 6, 3215-3224 (2019).

8. Rajendran, V. et al. Super broadband near-infrared phosphors with high radiant flux as future light sources for spectroscopy applications. ACS Energy Lett. 3, 2679-2684 (2018).

9. Lukovic, M. et al. LED-based vis-NIR spectrally tunable light source - the optimization algorithm. J. Eur. Optical Soc. Rapid Publ. 12, 19 (2016).

10. Gmachl, C. et al. Ultra-broadband semiconductor laser. Nature 415, 883-887 (2002).

11. Ye, X. et al. In Proceedings of SPIE 10758, Nonimaging Optics: Efficient Design for Illumination and Solar Concentration XV (SPIE, 2018).

12. Wadsworth, W. J. et al. Supercontinuum generation in photonic crystal fibers and optical fiber tapers: a novel light source. J. Optical Soc. Am. B 19, 2148-2155 (2002).

13. Blasse, G. \& Grabmaier, B. C. Luminescent Materials (Springer-Verlag, 1994).

14. Htein, L. et al. Amplification by white light-emitting diode pumping of largecore Er-doped fiber with 12 dB gain. Opt. Lett. 37, 4853-4855 (2012).

15. $\mathrm{Hu}$, J. et al. Highly efficient cascaded amplification using $\mathrm{Pr}^{3+}$-doped midinfrared chalcogenide fiber amplifiers. Opt. Lett. 40, 3687-3690 (2015).

16. Aitken, B. G., Dejneka, M. J. \& Powley, M. L. Tm-doped alkaline earth aluminate glass for optical amplification at $1460 \mathrm{~nm}$. J. Non Cryst. Solids 349, 115-119 (2004).

17. Marin, R. \& Jaque, D. Doping lanthanide ions in colloidal semiconductor nanocrystals for brighter photoluminescence. Chem. Rev. 121, 1425-1462 (2021).

18. Pan, G. C. et al. Doping lanthanide into perovskite nanocrystals: highly improved and expanded optical properties. Nano Lett. 17, 8005-8011 (2017).

19. Milstein, T. J., Kroupa, D. M. \& Gamelin, D. R. Picosecond quantum cutting generates photoluminescence quantum yields over $100 \%$ in ytterbium-doped $\mathrm{CsPbCl}_{3}$ nanocrystals. Nano Lett. 18, 3792-3799 (2018).

20. Zhou, D. L. et al. Cerium and ytterbium codoped halide perovskite quantum dots: a novel and efficient downconverter for improving the performance of silicon solar cells. Adv. Mater. 29, 1704149 (2017).

21. Kroupa, D. M. et al. Quantum-cutting ytterbium-doped $\mathrm{CsPb}\left(\mathrm{Cl}_{1-x} \mathrm{Br}_{x}\right)_{3}$ perovskite thin films with photoluminescence quantum yields over 190\%. ACS Energy Lett. 3, 2390-2395 (2018).

22. Wei, Y., Cheng, Z. Y. \& Lin, J. An overview on enhancing the stability of lead halide perovskite quantum dots and their applications in phosphor-converted LEDs. Chem. Soc. Rev. 48, 310-350 (2019).

23. Wang, X. C. et al. Perovskite quantum dots for application in high color gamut backlighting display of light-emitting diodes. ACS Energy Lett. 5, 3374-3396 (2020).

24. Creutz, S. E. et al. Colloidal nanocrystals of lead-free double-perovskite (elpasolite) semiconductors: synthesis and anion exchange to access new materials. Nano Lett. 18, 1118-1123 (2018).

25. Nila Nandha, K. \& Nag, A. Synthesis and luminescence of Mn-doped $\mathrm{Cs}_{2} \mathrm{~A}-$ $\mathrm{glnCl}_{6}$ double perovskites. Chem. Commun. 54, 5205-5208 (2018).

26. Zhou, B. et al. Efficient white photoluminescence from self-trapped excitons in $\mathrm{Sb}^{3+} / \mathrm{Bi}^{3+}$-codoped $\mathrm{Cs}_{2} \mathrm{NalnCl}_{6}$ double perovskites with tunable dualemission. ACS Energy Lett. 6, 3343-3351 (2021).

27. Volonakis, G. et al. $\mathrm{Cs}_{2} \ln \mathrm{AgCl}_{6}$ : a new lead-free halide double perovskite with direct band gap. J. Phys. Chem. Lett. 8, 772-778 (2017).

28. Meng, W. W. et al. Parity-forbidden transitions and their impact on the optical absorption properties of lead-free metal halide perovskites and double perovskites. J. Phys. Chem. Lett. 8, 2999-3007 (2017).

29. Liu, Y. et al. Lead-free double perovskite $\mathrm{CS}_{2} \mathrm{AgInCl}_{6}$. Angew. Chem. Int. Ed. 60 11592-11603 (2021)

30. Luo, J. J. et al. Efficient and stable emission of warm-white light from lead-free halide double perovskites. Nature 563, 541-545 (2018). 
31. Lee, W., Hong, S. \& Kim, S. Colloidal synthesis of lead-free silver-indium doubleperovskite $\mathrm{Cs}_{2} \mathrm{AglnCl}_{6}$ nanocrystals and their doping with lanthanide ions. J. Phys. Chem. C 123, 2665-2672 (2019).

32. Mahor, Y., Mir, W. J. \& Nag, A. Synthesis and near-infrared emission of Ybdoped $\mathrm{Cs}_{2} \mathrm{AglnCl}_{6}$ double perovskite microcrystals and nanocrystals. J. Phys. Chem. C 123, 15787-15793 (2019).

33. Chen, $\mathrm{N}$. et al. $\mathrm{Yb}$ - and $\mathrm{Mn}$-doped lead-free double perovskite $\mathrm{Cs}_{2} \mathrm{AgBiX}_{6}(\mathrm{X}=$ $\mathrm{Cl}^{-}, \mathrm{Br}^{-}$) nanocrystals. ACS Appl. Mater. Interfaces 11, 16855-16863 (2019).

34. Li, S. R. et al. Self-trapped exciton to dopant energy transfer in rare earth doped lead-free double perovskite. Adv. Opt. Mater. 7, 1901098 (2019).

35. Wang, C. Y. et al. Highly efficient lead-free (Bi, Ce)-codoped $\mathrm{Cs}_{2} \mathrm{Ag}_{0.4}$ $\mathrm{Na}_{0.6} \mathrm{InCl}_{6}$ double perovskites for white light-emitting diodes. Chem. Mater. 32, 7814-7821 (2020).

36. Schmitz, F. et al. Lanthanide-induced photoluminescence in lead-free $\mathrm{Cs}_{2} \mathrm{AgBiBr}_{6}$ bulk perovskite: insights from optical and theoretical investigations. J. Phys. Chem. Lett. 11, 8893-8900 (2020).

37. Arfin, $\mathrm{H}$. et al. $\mathrm{Bi}^{3+}-\mathrm{Ln}^{3+}(\mathrm{Ln}=\mathrm{Er}$ and $\mathrm{Yb})$ codoped $\mathrm{Cs}_{2} \mathrm{AglnCl}_{6}$ double perovskite near -infrared emitter. Angew. Chem. Int. Ed. 59, 11307-11311 (2020).

38. Liu, Y. et al. Incorporating rare-earth terbium(III) ions into $\mathrm{Cs}_{2} \mathrm{AgInCl}_{6}: \mathrm{Bi}$ nanocrystals toward tunable photoluminescence. Angew. Chem. Int. Ed. 59, 11634-11640 (2020).

39. Yao, M. M. et al. Improving lead-free double perovskite $\mathrm{Cs}_{2} \mathrm{NaBiCl}_{6}$ nanocrystal optical properties via ion doping. Adv. Opt. Mater. 8, 1901919 (2020).

40. Zhang, G. D. et al. Facile solution synthesis of $\mathrm{Bi}^{3+} / \mathrm{Yb}^{3+}$ ions co-doped $\mathrm{Cs}_{2} \mathrm{Na}_{0.6} \mathrm{Ag}_{0.4} \mathrm{InCl}_{6}$ double perovskites with near-infrared emission. Dalton Trans. 49, 15231-15237 (2020).

41. Zeng, Z. C. et al. Multimodal luminescent $\mathrm{Yb}^{3+} / \mathrm{Er}^{3+} / \mathrm{Bi}^{3+}$-doped perovskite single crystals for $\mathrm{X}$-ray detection and anti-counterfeiting. Adv. Mater. 32, 2004506 (2020).

42. Yang, S. et al. Bi and $\mathrm{Yb}$ codoped $\mathrm{Cs}_{2} \mathrm{Ag}_{0.6} \mathrm{Na}_{0.4} \mathrm{InCl}_{6}$ microcrystals: visible to near-infrared fluorescence for thermometry. J. Phys. Chem. C 125, 10431-10440 (2021).

43. Zhang, R. L. et al. All-inorganic rare-earth halide double perovskite single crystals with highly efficient photoluminescence. Adv. Opt. Mater. 9, 2100689 (2021).

44. Yin, $H$. et al. Lead-free rare-earth double perovskite $\mathrm{Cs}_{2} \mathrm{AgIn}_{1-\gamma-x} \mathrm{Bi}_{x} \mathrm{~L} \mathrm{a}_{\gamma} \mathrm{Cl} \mathrm{l}_{6}$ nanocrystals with highly efficient warm-white emission. Sci. China Mater. 64, 2667-2674 (2021).
45. Wang, Z. L. et al. Cerium doping double perovskite scintillator for sensitive X-ray detection and imaging. Chem. A Eur. J. 27, 9071-9076 (2021).

46. Zhou, J. et al. Manipulation of $\mathrm{Bi}^{3+} / \mathrm{In}^{3+}$ transmutation and $\mathrm{Mn}^{2+}$-doping effect on the structure and optical properties of double perovskite $\mathrm{Cs}_{2} \mathrm{NaBi}_{1}$. $x \ln { }_{x} \mathrm{Cl}_{6}$. Adv. Opt. Mater. 7, 1801435 (2019).

47. Han, P. G. et al. Size effect of lead-free halide double perovskite on luminescence property. Sci. China Chem. 62, 1405-1413 (2019).

48. $\mathrm{Hu}, \mathrm{Q}$. S. et al. Tunable color temperatures and efficient white emission from $\mathrm{Cs}_{2} \mathrm{Ag}_{1-x} \mathrm{Na}_{x} \mathrm{n}_{1-y} \mathrm{Bi}_{y} \mathrm{Cl}_{6}$ double perovskite nanocrystals. Small 15, 1903496 (2019).

49. Zhu, W. J. et al. Low-dose real-time $X$-ray imaging with nontoxic double perovskite scintillators. Light Sci. Appl. 9, 112 (2020).

50. Yang, B. et al. Lead-free direct band gap double-perovskite nanocrystals with bright dual-color emission. J. Am. Chem. Soc. 140, 17001-17006 (2018).

51. Kubicki, D. J. et al. Phase segregation in Cs-, Rb- and K-doped mixed-cation $(\mathrm{MA})_{x}(\mathrm{FA})_{1-x} \mathrm{Pbl}_{3}$ Hybrid perovskites from solid-state NMR. J. Am. Chem. Soc. 139, 14173-14180 (2017).

52. Xiang, W. C. et al. Europium-doped $\mathrm{CsPb}_{2} \mathrm{Br}$ for stable and highly efficient inorganic perovskite solar cells. Joule 3, 205-214 (2019).

53. Karmakar, A. et al. Tailorable indirect to direct band-gap double perovskites with bright white-light emission: decoding chemical structure using solidstate NMR. J. Am. Chem. Soc. 142, 10780-10793 (2020).

54. Awater, R. H. P. \& Dorenbos, P. The $\mathrm{Bi}^{3+} 6 \mathrm{~s}$ and $6 \mathrm{p}$ electron binding energies in relation to the chemical environment of inorganic compounds. J. Lumin. $\mathbf{1 8 4}$ 221-231 (2017)

55. Liu, Y. et al. Design optimization of lead-free perovskite $\mathrm{CS}_{2} \mathrm{Ag}_{\mathrm{InCl}}$ :Bi nanocrystals with $11.4 \%$ photoluminescence quantum yield. Chem. Mater. 31 3333-3339 (2019).

56. Pan, Q. W. et al. Engineering tunable broadband near-infrared emission in transparent rare-earth doped nanocrystals-in-glass composites via a bottomup strategy. Adv. Optical Mater. 7, 1801482 (2019).

57. Lin, J. et al. Research progresses in preparation and applications of $\mathrm{CsPbX}_{3}$ $(\mathrm{X}=\mathrm{Cl}, \mathrm{Br}, \mathrm{I})$ perovskite quantum dots-embedded glass. Chin. J. Lumin. $\mathbf{4 2}$ 1331-1344 (2021).

58. Lin, J. D. et al. Perovskite quantum dots glasses based backlit displays. ACS Energy Lett. 6, 519-528 (2021). 